\title{
Computational Evaluation of Intermolecular Interaction in Poly(Styrene-Maleic Acid)- Water Complexes Using Density Functional Theory
}

\author{
Daru Seto Bagus Anugrah ${ }^{*}$, Laura Virdy Darmalim ${ }^{1}$, Permono Adi Putro ${ }^{2}$, Liana Dewi Nuratikah ${ }^{3}$, \\ Nurwarrohman Andre Sasongko ${ }^{3}$, Parsaoran Siahaan ${ }^{3}$, and Adi Yulandi ${ }^{1}$ \\ ${ }^{1}$ Department of Biotechnology, Faculty of Biotechnology, Atma Jaya Catholic University of Indonesia, \\ BSD Campus, Tangerang 15345, Indonesia
}

${ }^{2}$ Department of Physics, Faculty of Mathematics and Natural Sciences, IPB University, Jl. Meranti, Kampus IPB Dramaga, Bogor 16680, Indonesia

${ }^{3}$ Department of Chemistry, Faculty of Sciences and Mathematics, Diponegoro University, Jl. Prof. H. Soedarto, S.H., Tembalang, Semarang 50275, Indonesia

\section{* Corresponding author: \\ email:daru.seto@atmajaya.ac.id \\ Received: July 26, 2021 \\ Accepted: September 13, 2021}

DOI: $10.22146 /$ ijc. 67961

\begin{abstract}
The high application of Poly(styrene-maleic acid) (PSMA) in an aqueous environment, such as biomedical purposes, makes the interaction between PSMA and water molecules interesting to be investigated. This study evaluated the conformation, the hydrogen bond network, and the stabilities of all the possible intermolecular interactions between PSMA with water (PSMA- $\left.\left(\mathrm{H}_{2} \mathrm{O}\right)_{n}, n=1-5\right)$. All calculations were executed using the density functional theory (DFT) method at B3LYP functional and the 6-311G ${ }^{* *}$ basis set. The energy interaction of PSMA-( $\left.\mathrm{H}_{2} \mathrm{O}\right)_{5}$ complex was $-56.66 \mathrm{kcal} / \mathrm{mol}$, which is classified as high hydrogen bond interaction. The Highest Occupied Molecular Orbital (HOMO) Lowest Unoccupied Molecular Orbital (LUMO) energy gap decreased with the rise in the number of $\mathrm{H}_{2} \mathrm{O}$ molecules, representing a more reactive complex. The strongest hydrogen

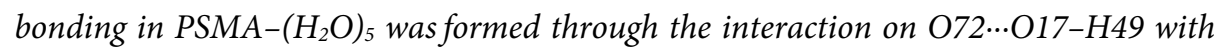
stabilizing energy of $50.32 \mathrm{kcal} / \mathrm{mol}$, that analyzed by natural bond orbital (NBO) theory. The quantum theory atoms in molecules (QTAIM) analysis showed that the hydrogen bonding $\left(E_{H B}\right)$ value on $072 \cdots O 17-H 49$ was $-14.95 \mathrm{kcal} / \mathrm{mol}$. All computational data revealed that PSMA had moderate to high interaction with water molecules that indicated the water molecules were easily transported and kept in the PSMA matrix.
\end{abstract}

Keywords: Density Functional Theory; hydrogen bonding; poly(styrene-maleic acid); water

\section{- INTRODUCTION}

The increasing interest in synthetic polymers in various area is very high because it has uniform properties [1-3]. The polydispersity index of synthetic polymers can be close to 1 , which is difficult to obtain from natural polymers. Therefore, synthetic polymers are more uniform than natural polymers. However, not all synthetic polymers are compatible with biological materials. One of the remarkable synthetic polymers is poly(styrene-maleic acid) (PSMA) due to its biological properties. The structure of PSMA can be controlled and manipulated, which makes PSMA is used for wideranging purposes. Research showed that PSMA was engineered as drug carriers, such as nano-micelle and hydrogel [4-7]. In its structure, PSMA has many carboxyl groups that can play a role in hydrogen bonding interactions to bind water molecules, proteins, and even drugs [8]. Recently, intermolecular interactions have been studied intensively experimentally and theoretically.

Theoretical investigations using computational can fully understand the nature and site of interaction between molecules at the level of molecules or atoms. The investigation with quantum mechanical 
calculations allows the study to provide complete ideas about the mechanism at the molecular level. The density functional theory (DFT) offers an achievable computational method to include the role of electrons in quantum computations. The DFT computation can be used in various fields, such as medicine, environment, and energy. The computation can be carried out using small to large molecules such as $\beta$-Cyclodextrin and polymers [9-13]. Ferid's research team modeled the interactions that occur in the urea-water complex [10].

Computational studies of polymers usually use dimer structures due to the limitations of the computational approach [14-15]. In addition, the investigation of the dimer structure did not differ significantly from that of the trimer and oligomers [16]. Computational studies were carried out to illustrate chitosan derivatives as gene carriers [17]. Researchers also succeeded in explaining the interaction of the polyelectrolyte complex between alginate and chitosan dimers [15]. Interactions between dimer chitosan and essential amino acids were calculated to understand and predict drug delivery mechanisms by Deka and Bhattacharyya [12].

PSMA is a versatile synthetic polymer that has extensive application in aqueous solutions. Therefore, the interactions of PSMA with water molecules are fascinating to be investigated computationally. In the present study, the stabilized interactions between the PSMA and water molecules were studied by DFT. PSMA dimer structure was chosen to represent the PSMA polymer. A water microsolvation approach was used by adding one to five water molecules. This study aims to investigate the intermolecular hydrogen bond interaction in PSMA- $\left(\mathrm{H}_{2} \mathrm{O}\right)_{\mathrm{n}}$ complexes by DFT/B3LYP 6-311G** with NBO, AIM, and NCI analyses. This research can be used for the development of PSMA polymer in the future.

\section{- COMPUTATIONAL DETAILS}

\section{Density Functional Theory Calculation}

In the current study, the computational calculations of all proposed PSMA dimers and water molecules $(\mathrm{n}=$ 1-5) were completed with the density functional theory (DFT) by NWChem 6.8 program $[16,18]$. A microsolvation approach was conducted by adding one to five water molecules [15]. The lowest energy of PSMA dimer and water was obtained by individually structure optimization. The optimized molecular structure of PSMA dimer was then interacted with $\left(\mathrm{H}_{2} \mathrm{O}\right)_{\mathrm{n}}$ molecules to reach the lowest energy of PSMA- $\left(\mathrm{H}_{2} \mathrm{O}\right)_{n}$ complexes. The stability of the molecule was evaluated by frequencies calculation. A positive value of frequency indicates that the molecule is already stable. Furthermore, Basis Set Superposition Error (BSSE) and zero-point correction to energy (ZPE) were also calculated to determine the interaction energy with the full counterpoise method [19-20]. The interaction energy was received by Eq. (1).

$\mathrm{E}_{\text {int }}=\mathrm{E}_{\text {PSMA- }\left(\mathrm{H}_{2} \mathrm{O}\right)_{\mathrm{n}}}-\left(\mathrm{E}_{\text {PSMA }}+\mathrm{E}_{\left(\mathrm{H}_{2} \mathrm{O}\right)_{\mathrm{n}}}\right)$

$$
+\mathrm{E}_{\mathrm{BSSE}_{-} \mathrm{PSMA}-\left(\mathrm{H}_{2} \mathrm{O}\right)_{\mathrm{n}}}
$$

$\mathrm{E}_{\mathrm{PSMA} / \mathrm{H}_{2} \mathrm{O}}$ was the lowest energy of PSMA- $\left(\mathrm{H}_{2} \mathrm{O}\right)_{n}$ complexes while $\mathrm{E}_{\text {PSMA }}$ and $\mathrm{E}_{\mathrm{H}_{2} \mathrm{O}}$ were the lowest energy of PSMA dimer and $\mathrm{H}_{2} \mathrm{O}$, respectively.

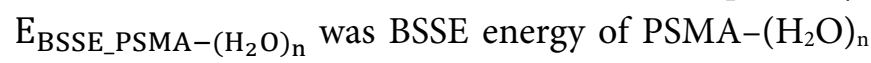
complexes. All calculations were conducted by the DFT method with the hybrid quality of Becke's threeparameter functional (B3LYP) and the 6-311G (d,p) basis set. The PSMA- $\left(\mathrm{H}_{2} \mathrm{O}\right)_{n}$ complex interactions are non-covalent bonds, including hydrogen bonds [21]. Therefore, the calculation of the interaction energy helped assign the type of hydrogen bond strength.

\section{Reactivity of the Complexes}

In this study, Highest Occupied Molecular Orbital (HOMO) - Lowest Unoccupied Molecular Orbital (LUMO) energy was calculated to determine the reactivity of a molecule in the process of electron transfer in PSMA hydrogel [12,22]. HOMO energy is related to the process of releasing or donating electrons (ionization energy, I), while LUMO energy is related to the electrons' receiving process (affinity energy, A) (Eq. (2) and (3)) [23-24]. The energy gap of HOMO-LUMO energy was determined by Eq. (4). The electronegativity $(\chi)$ of the molecule was calculated by HOMO and LUMO energy values (Eq. (5)).

$\mathrm{I}=-\mathrm{E}_{\mathrm{HOMO}}$

$A=-E_{\text {LUMO }}$ 
$\Delta \mathrm{E}=\mathrm{E}_{\mathrm{LUMO}}-\mathrm{E}_{\mathrm{HOMO}}$

$\chi=\frac{1}{2}(\mathrm{I}+\mathrm{A})$

\section{Natural Bond Orbital (NBO) Analysis}

NBO measurements were conducted to evaluate the charge distribution, interaction of electron delocalization, and type of interaction binding energy in PSMA and $\left(\mathrm{H}_{2} \mathrm{O}\right)_{\mathrm{n}}$ by second-order perturbation theory [12-13,15]. The calculation was conducted by NBO 7.0 software for PSMA- $\left(\mathrm{H}_{2} \mathrm{O}\right)_{\mathrm{n}}$ complexes. The orbital stabilizing energy $\left(\mathrm{E}^{(2)}\right)$ associated with the delocalization donor (i) $\rightarrow$ acceptor (j) was calculated according to Eq. (6).

$E^{(2)}=\Delta E_{i j}=q_{i} \frac{F_{i, j}^{2}}{E_{i}-E_{j}}$

where $q_{i}$ is the occupancy of orbital, $F_{i, j}^{2}$ is NBO Fock matrix element, $E_{i}$ is the energy of the $\mathrm{NBO}$ donor, and $\mathrm{E}_{j}$ is the energy of the NBO acceptor.

\section{Quantum Theory Atom in Molecule (QTAIM) Analysis}

The QTAIM analysis was conducted to support NBO analysis by calculating hydrogen bonding energy at Bond Critical Point (BCP) [25]. The analysis was obtained by Multiwfn 3.8 program. Parameters at the BCP that could be collected by QTAIM calculation were electron density $\left(\rho_{(\mathrm{BCP})}\right)$, Laplacian of the charge density $\left(\nabla^{2} \rho\right)$, ellipticity index $(\varepsilon)$, components of Laplacian in $\mathrm{x}, \mathrm{y}, \mathrm{z}$ $\left(\lambda_{1}, \lambda_{2}, \lambda_{3}\right)$, electronic energy density $\left(\mathrm{H}_{(\mathrm{BCP})}\right)$, kinetic energy density $\left(\mathrm{G}_{(\mathrm{BCP})}\right)$, potential energy density $\left(\mathrm{V}_{(\mathrm{BCP})}\right)$, and $\mathrm{H}-$ bond binding energy $\left(\mathrm{E}_{\mathrm{HB}}\right)$ [26]. The equation of each parameter was presented in Eq. (7-9).

$\nabla^{2} \rho=\lambda_{1}+\lambda_{2}+\lambda_{3}$

$\mathrm{H}_{(\mathrm{BCP})}=\mathrm{G}_{(\mathrm{BCP})}+\mathrm{V}_{(\mathrm{BCP})}$

$\mathrm{E}_{\mathrm{HB}}=\left(-223.8 \times \rho_{(\mathrm{BCP})}\right)+0.7423$ (for neutral H-bond)

The relation between the values of $\nabla^{2} \rho$ and $\mathrm{H}_{(\mathrm{BCP})}$ could identify the type of interaction that occurs in BCP. A weak covalent interaction (strong electrostatic bond) is indicated by $\nabla^{2} \rho(+)$ and $\mathrm{H}_{(\mathrm{BCP})}(+)$. A strong interaction (strong covalent bond) is indicated by $\nabla^{2} \rho(-)$ and $\mathrm{H}_{(\mathrm{BCP})}$ $(-)$. A medium strength (partially covalent bond) is indicated by $\nabla^{2} \rho(+)$ and $\mathrm{H}_{(\mathrm{BCP})}(-)$ [16]. An absolute ratio value of kinetic and potential energy density $(|\mathrm{V} / \mathrm{G}|)$ is also a parameter that could categorize interactions. The value of $|V / G|<1$ interprets a weak interaction, the value of $1<|\mathrm{V} / \mathrm{G}|<2$ interprets a medium, and the value of $|V / G|>2$ interprets a strong interaction $[9,16]$.

\section{Reduced Density Gradient (RDG) and Non- covalent Interaction $(\mathrm{NCl})$}

RDG and NCI analyses are used to describe the non-covalent interactions in PSMA and PSMA- $\left(\mathrm{H}_{2} \mathrm{O}\right)_{n}$ complexes, such as steric repulsion, Van der Waals $(\mathrm{VdW})$ interactions, and hydrogen bonding [27]. RDG is obtained with Eq. (10).

$\mathrm{RDG}=\frac{1}{2\left(3 \pi^{2}\right)^{1 / 3}} \frac{\left|\nabla \rho_{(\mathrm{r})}\right|}{\rho_{(\mathrm{r})}{ }^{4 / 3}}$

where $\left|\nabla \rho_{(\mathrm{r})}\right|$ is the gradient norm of the electron density and $\rho_{(\mathrm{r})}$ is electron density. RDG graph and color-filled isosurface of the complexes are produced by Multiwfn 3.8 and VMD software [28]. Values of RDG and $\rho_{(\mathrm{r})}$ provide an analysis of non-covalent interactions in each complex through a 2D scatter graph. Additionally, the second largest eigenvalue of the electron density Hessian matrix $\left(\lambda_{2}\right)$ at position $r$ is an essential parameter in NCI analysis [29]. Based on the equation $\rho_{(\mathrm{r})}$, the sign of $\lambda_{2}$ changes. Thus, sign $\left(\lambda_{2}\right) \rho_{(\mathrm{r})}$ versus RDG value are plotted on the scatter graph. Strong repulsions are indicated by $\left(\lambda_{2}\right) \rho_{(\mathrm{r})}>0$ and $\rho_{(\mathrm{r})}>0$, while strong attractions are based on $\left(\lambda_{2}\right) \rho_{(\mathrm{r})}<0$ and $\rho_{(\mathrm{r})}>0$. Meanwhile, VdW interactions (the weak interaction) are presented in the value of $\left(\lambda_{2}\right) \rho_{(\mathrm{r})}$ and $\rho_{(\mathrm{r})} \approx 0[29-31]$.

\section{- RESULTS AND DISCUSSION}

\section{Optimized Structure of PSMA and Water Molecules}

The geometry of molecules was measured at the level theory B3LYP/6-311G ${ }^{* *}$ to obtain an optimized structure with minimum energy. In this study, the dimer of PSMA was chosen to represent the PSMA polymer chain. Computational-based researchers also conducted the dimer calculation method due to the enthalpy and interaction energy between dimers, trimers, and oligomers to water were similar [15-16,32-34]. A microsolvation approach investigated the PSMAsolvent interactions. One to five water molecules interacted with PSMA. NWChem software was used to 
obtain the optimized structure of PSMA and water (Fig. 1 (a) and 1(c), respectively).

The optimized structure of PSMA showed linear structure due to single bonding $(\mathrm{C}-\mathrm{C})$ in the backbone. The optimized structure displayed one intramolecular

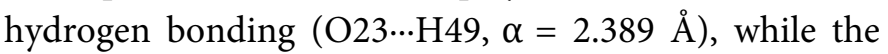
distance of $\mathrm{C} 2-\mathrm{C} 5, \mathrm{C} 3-\mathrm{C} 4, \mathrm{C} 5-\mathrm{O} 17$, and $\mathrm{C} 4-\mathrm{O} 16$ were $1.521,1.525,1.351$, and $1.353 \AA$, respectively. The theoretical data were in good agreement with experimental data of the monomer crystal structure [35]. The experimental research showed that the $\mathrm{C}$-atoms' distances were 1.52 and $1.51 \AA$, and the $\mathrm{C}-\mathrm{O}$ distances were 1.28 and $1.31 \AA$. The molecular electrostatic potential (MEP) of the PSMA structure was shown as the active site to conduct interactions with water molecules (Fig. 1(b)). The red and blue colors in the MEP figure indicate the highest and lowest total density electron in structure, which reflect the negative and positive sides, respectively. O17 and O23 in the PSMA structure showed a negative side (nucleophile), whereas H49 and H64 presented a positive side (electrophile). The interaction probabilities between PSMA and $\left(\mathrm{H}_{2} \mathrm{O}\right)_{\mathrm{n}}$ around O17, $\mathrm{O} 23, \mathrm{H} 49$, and $\mathrm{H} 64$ were higher than others due to a difference in charge and no obstacles. O1 presented the negative side in the water molecule, while $\mathrm{H} 2$ and $\mathrm{H} 3$ were the opposite (Fig. 1(d)).

\section{PSMA- $\left(\mathrm{H}_{2} \mathrm{O}\right)_{n}$ Complexes Interaction}

The optimized geometry of PSMA- $\left(\mathrm{H}_{2} \mathrm{O}\right)_{n}$ complexes were investigated for knowing how strong the interaction between PSMA structure and water molecules is. The most stable geometry of PSMA$\left(\mathrm{H}_{2} \mathrm{O}\right)_{n}$ complexes were given in Fig. S1. The complex structure showed that PSMA- $\left(\mathrm{H}_{2} \mathrm{O}\right)_{n}$ complexes were linked by the hydrogen bonding $\mathrm{O}-\mathrm{H} \cdots \mathrm{H}$ and $\mathrm{C}=\mathrm{O} \cdots \mathrm{H}$ through carboxylate groups. In addition to the bonds between molecules PSMA and water, there were also bonds between water-water.

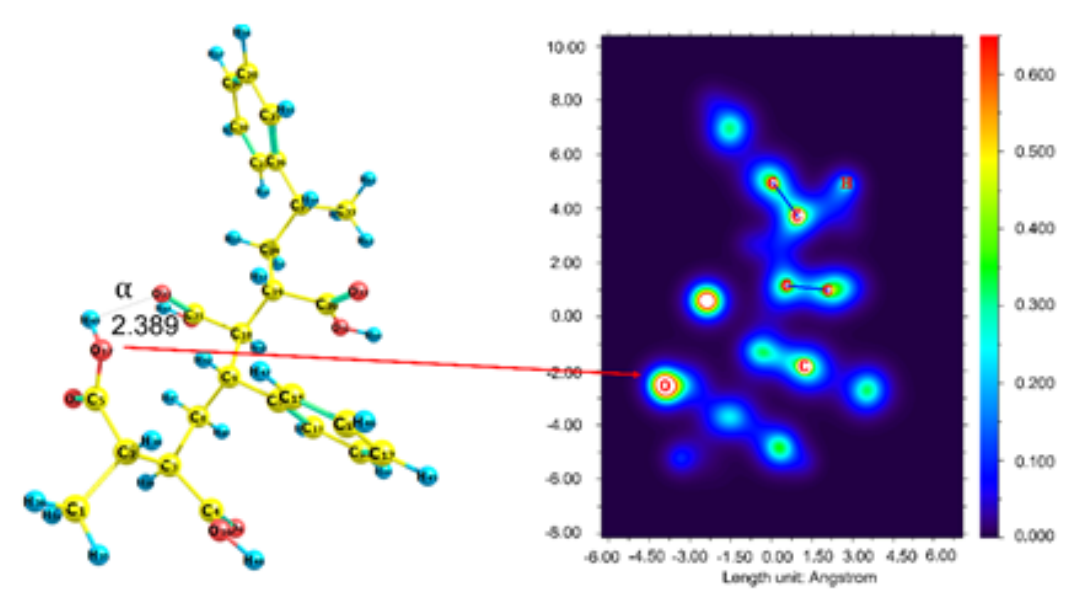

(a) (b)

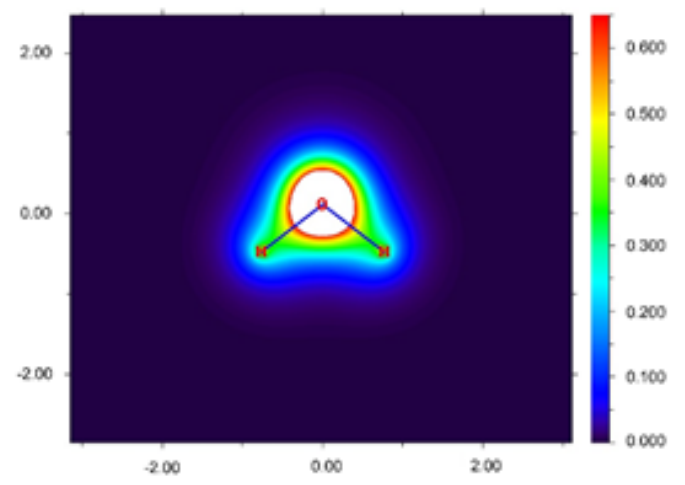

(d)

Fig 1. Optimized geometry and MEP of PSMA (a, b) and $\mathrm{H}_{2} \mathrm{O}(\mathrm{c}, \mathrm{d})$ 
The hydrogen bond lengths and interaction energy of PSMA- $\left(\mathrm{H}_{2} \mathrm{O}\right)_{n}$ complexes were presented in Table 1 . One hydrogen bond in the water molecule interacted with the carbonyl group $(\mathrm{C}=\mathrm{O})$ via a hydrogen bond $(\mathrm{O} 7 \cdots \mathrm{H} 66$, $\left.\mathrm{r}_{\mathrm{OH}}=1.904 \AA\right)$. Meanwhile, the other hydrogen bond $(\mathrm{O} 65 \cdots \mathrm{H} 64)$ was a bit shorter $\left(\mathrm{r}_{\mathrm{OH}}=1.652 \AA\right)$. The intramolecular hydrogen bond in PSMA geometry appeared between $\mathrm{O} 23 \cdots \mathrm{H} 49\left(\mathrm{r}_{\mathrm{OH}}=1.986 \AA\right)$. Three hydrogen bonds stabilized the PSMA- $\left(\mathrm{H}_{2} \mathrm{O}\right)_{2}$ complex. The length of the intermolecular hydrogen bond varies from 1.886-1.986 $\AA$, and a bond was the interaction between water molecules $\left(\mathrm{r}_{\mathrm{OH}}=1.970 \AA\right)$. The intramolecular hydrogen force in the PSMA- $\left(\mathrm{H}_{2} \mathrm{O}\right)_{n}$ complex decreased when water molecules appeared. The distance of $\mathrm{O} 23 \cdots \mathrm{H} 49$ in PSMA- $\left(\mathrm{H}_{2} \mathrm{O}\right)_{2}$ complex was more extended $\left(\mathrm{r}_{\mathrm{OH}}=2.116 \AA\right)$ than PSMA- $\left(\mathrm{H}_{2} \mathrm{O}\right)_{1}$ complex, which was due to the interaction of $\mathrm{O} 23$ and $\mathrm{H} 49$ with water molecules. Furthermore, the addition of water molecules in the PSMA- $\left(\mathrm{H}_{2} \mathrm{O}\right)_{3}$, PSMA- $\left(\mathrm{H}_{2} \mathrm{O}\right)_{4}$, and PSMA- $\left(\mathrm{H}_{2} \mathrm{O}\right)_{5}$ complexes caused a cyclic formation involving several water molecules and PSMA molecules. An increase in the number of water molecules raised the number of hydrogen bonds and shortened the distance. Moreover, the data displayed all hydrogen bond lengths in PSMA- $\left(\mathrm{H}_{2} \mathrm{O}\right)_{\mathrm{n}}$ complexes ranged from $1.517 \AA$ to 1.96 $\AA$, categorized as strong to medium hydrogen bonds $[13,16]$. As a comparison, the calculation with the ab initio methods, such as Hartree-Fock (HF) and Secondorder Møller-Plesset perturbation theory (MP2), were conducted to determine the optimization energy of PSMA- $\left(\mathrm{H}_{2} \mathrm{O}\right)_{1}\left(\mathrm{E}_{\mathrm{opt}_{\text {PSMA } \cdots\left(\mathrm{H}_{2} \mathrm{O}\right)_{1}}}\right)$ (Table S1). The energy from DFT was lower than HF and MP2, indicating that the calculation with the DFT method was more stable and reliable for this study.

Hydrogen bond interaction is classified based on the energy value. The energy above $20 \mathrm{kcal} / \mathrm{mol}$ is classified as a strong bond, while the energy of $4-20 \mathrm{kcal} / \mathrm{mol}$ is classified as a moderate bond. A weak bond is indicated by the energy below $4 \mathrm{kcal} / \mathrm{mol}$. PSMA- $\left(\mathrm{H}_{2} \mathrm{O}\right)_{5}$ and PSMA- $\left(\mathrm{H}_{2} \mathrm{O}\right)_{4}$ were categorized as a strong hydrogen bond, whereas the rest of PSMA- $\left(\mathrm{H}_{2} \mathrm{O}\right)$ complexes were classified as a moderate hydrogen bond interaction. The interaction energy of the PSMA- $\left(\mathrm{H}_{2} \mathrm{O}\right)_{n}$ complexes escalated as the number of water
Table 1. The interaction energy of PSMA- $\left(\mathrm{H}_{2} \mathrm{O}\right)_{n}$ complexes

\begin{tabular}{|c|c|c|}
\hline Complexes & Hydrogen bond $(\AA)$ & $\begin{array}{c}\text { Interaction energy } \\
(\mathrm{kcal} / \mathrm{mol})\end{array}$ \\
\hline \multirow{2}{*}{ PSMA- $\left(\mathrm{H}_{2} \mathrm{O}\right)_{1}$} & $\mathrm{r}(\mathrm{O} 7 \cdots \mathrm{H} 66)=1.904$ & \multirow{2}{*}{-12.517} \\
\hline & $\mathrm{r}(\mathrm{O} 65 \cdots \mathrm{H} 64)=1.652$ & \\
\hline \multirow{3}{*}{ PSMA- $\left(\mathrm{H}_{2} \mathrm{O}\right)_{2}$} & $\mathrm{r}(\mathrm{O} 7 \cdots \mathrm{H} 66)=1.886$ & \multirow{3}{*}{-21.725} \\
\hline & $\mathrm{r}(\mathrm{O} 65 \cdots \mathrm{H} 64)=1.986$ & \\
\hline & $\mathrm{r}(\mathrm{O} 65 \cdots \mathrm{H} 68)=1.970$ & \\
\hline \multirow{6}{*}{ PSMA- $\left(\mathrm{H}_{2} \mathrm{O}\right)_{3}$} & $\mathrm{r}(\mathrm{O} 7 \cdots \mathrm{H} 66)=1.795$ & \multirow{6}{*}{-32.655} \\
\hline & $\mathrm{r}(\mathrm{O} 65 \cdots \mathrm{H} 64)=1.844$ & \\
\hline & $\mathrm{r}(\mathrm{O} 23 \cdots \mathrm{H} 67)=1.929$ & \\
\hline & $\mathrm{r}(\mathrm{O} 65 \cdots \mathrm{H} 68)=1.795$ & \\
\hline & $\mathrm{r}(\mathrm{O} 69 \cdots \mathrm{H} 73)=1.710$ & \\
\hline & $\mathrm{r}(\mathrm{O} 72 \cdots \mathrm{H} 49)=1.605$ & \\
\hline \multirow{7}{*}{ PSMA- $\left(\mathrm{H}_{2} \mathrm{O}\right)_{4}$} & $\mathrm{r}(\mathrm{O} 7 \cdots \mathrm{H} 66)=1.785$ & \multirow{7}{*}{-47.474} \\
\hline & $\mathrm{r}(\mathrm{O} 65 \cdots \mathrm{H} 76)=1.766$ & \\
\hline & $\mathrm{r}(\mathrm{O} 23 \cdots \mathrm{H} 67)=1.815$ & \\
\hline & $\mathrm{r}(\mathrm{O} 65 \cdots \mathrm{H} 68)=1.814$ & \\
\hline & $\mathrm{r}(\mathrm{O} 69 \cdots \mathrm{H} 73)=1.745$ & \\
\hline & $\mathrm{r}(\mathrm{O} 72 \cdots \mathrm{H} 49)=1.543$ & \\
\hline & $\mathrm{r}(\mathrm{O} 74 \cdots \mathrm{H} 64)=1.617$ & \\
\hline \multirow{9}{*}{ PSMA- $\left(\mathrm{H}_{2} \mathrm{O}\right)_{5}$} & $\mathrm{r}(\mathrm{O} 7 \cdots \mathrm{H} 66)=1.749$ & \multirow{9}{*}{-56.660} \\
\hline & $\mathrm{r}(\mathrm{O} 65 \cdots \mathrm{H} 76)=1.760$ & \\
\hline & $\mathrm{r}(\mathrm{O} 23 \cdots \mathrm{H} 67)=1.869$ & \\
\hline & $\mathrm{r}(\mathrm{O} 65 \cdots \mathrm{H} 79)=1.771$ & \\
\hline & $\mathrm{r}(\mathrm{O} 69 \cdots \mathrm{H} 73)=1.692$ & \\
\hline & $\mathrm{r}(\mathrm{O} 72 \cdots \mathrm{H} 49)=1.521$ & \\
\hline & $\mathrm{r}(\mathrm{O} 23 \cdots \mathrm{H} 71)=1.957$ & \\
\hline & $\mathrm{r}(\mathrm{O} 74 \cdots \mathrm{H} 64)=1.617$ & \\
\hline & $\mathrm{r}(\mathrm{O} 78 \cdots \mathrm{H} 68)=1.712$ & \\
\hline
\end{tabular}

molecules increased. The high water uptake is essential for a material to be used as a water-based material $[1,36-$ 38]. Besides, this particular examination revealed that the increase in water molecules further augmented the hydrogen bonds formed, shortened the hydrogen bonds, and enhanced the interaction energy in PSMA- $\left(\mathrm{H}_{2} \mathrm{O}\right)_{n}$ complexes. These data showed that water molecules are maintained in the PSMA matrix through strong bonds.

The results of modeling the interaction energy of PSMA- $\left(\mathrm{H}_{2} \mathrm{O}\right)_{n}$ complexes are restricted to a minimum of five water molecules. It was selected to represent a microsolvation model in the gas phase calculations [15]. The result may change if $\mathrm{H}_{2} \mathrm{O}$ molecules are increased 
(e.g., 50 to 100 molecules). The changes are due to increased intermolecular forces, dispersion, many-body effect, etc. [15,39-40]. Moreover, increasing the number of molecules is modeled by DFT can elevate the computational cost. Nevertheless, this simple approach allowed observing the PSMA- $\left(\mathrm{H}_{2} \mathrm{O}\right)_{\mathrm{n}}$ complexes properties. The calculations using dimer structure and small molecules ( 1 to 5 molecules) had been carried out by researchers to study optimized structures, properties, and interactions mechanisms [10,13,15-16]. Therefore, the data in this study could still be relied upon by future comprehension computational investigations carried out with elaboration of solvation models.

The construction of intermolecular hydrogen bonds in the complex structures influenced the intramolecular structure of PSMA. The hydration process tended to weaken the $\mathrm{C}=\mathrm{O}$ and $\mathrm{O}-\mathrm{H}$ bonds of PSMA. The increase in bond length indicated this. Table 2 presented $\mathrm{C}=\mathrm{O}$ and $\mathrm{O}-\mathrm{H}$ bond lengths in the PSMA structure before and after hydration. These results also showed that PSMA could dissociate in the presence of one water molecule, which could be seen at the O34-H64 bond length of more than $1 \AA$ A. In addition, $\mathrm{H} 64$ was more easily dissociated than $\mathrm{H} 49$.

\section{Parameters Reactivity of the Complexes}

Molecular reactivity can be predicted by means of molecular orbital theory. Quantum chemical parameters that describe the reactivity of molecules are electron affinity (A), ionization energy (I), and electronegativity $(\chi)$. The parameters were used to determine the HOMO and LUMO energies. HOMO and LUMO energy describe the molecular ability to donate and receive electrons, respectively [23]. The energy gap between HOMO and LUMO defines the chemical activities of molecules. All molecular parameters are presented in Table 3.

The HOMO-LUMO energy gap on the PSMA complex decreased due to the presence of one water molecule $(6.04 \rightarrow 5.8 \mathrm{eV})$. Then, the value slightly increased to $6.47 \mathrm{eV}$ on PSMA- $\left(\mathrm{H}_{2} \mathrm{O}\right)_{2}$. The addition of two water molecules on PSMA presented the greatest $\Delta \mathrm{E}$. The energy gap gradually declines as the water molecules increase. The energy gap value of PSMA$\left(\mathrm{H}_{2} \mathrm{O}\right)_{3}$, PSMA- $\left(\mathrm{H}_{2} \mathrm{O}\right)_{4}$, and the PSMA- $\left(\mathrm{H}_{2} \mathrm{O}\right)_{5}$ were $6.44,5.84$, and $5.87 \mathrm{eV}$, respectively. A higher $\Delta \mathrm{E}$ indicated that the complex was harder to transfer electrons. On the other hand, a lower $\Delta \mathrm{E}$ showed the complex was easier to transfer electrons [41]. Compared

Table 2. Bond length detail of PSMA and PSMA- $\left(\mathrm{H}_{2} \mathrm{O}\right)_{\mathrm{n}}$ complexes

\begin{tabular}{lcccc}
\hline \multirow{2}{*}{ Complexes } & \multicolumn{4}{c}{ Bond length $(\AA)$} \\
\cline { 2 - 5 } & $\mathrm{C} 5=\mathrm{O} 7$ & $\mathrm{C} 21=\mathrm{O} 23$ & $\mathrm{O} 17-\mathrm{H} 49$ & $\mathrm{O} 34-\mathrm{H} 64$ \\
\hline PSMA & 1.2133 & 1.2156 & 0.9738 & 0.9736 \\
PSMA- $\left(\mathrm{H}_{2} \mathrm{O}\right)_{1}$ & 1.2219 & 1.2320 & 0.9777 & 1.0104 \\
PSMA- $\left(\mathrm{H}_{2} \mathrm{O}\right)_{2}$ & 1.2225 & 1.2289 & 0.9755 & 0.9984 \\
PSMA- $\left(\mathrm{H}_{2} \mathrm{O}\right)_{3}$ & 1.2320 & 1.2267 & 0.9914 & 1.0114 \\
PSMA- $\left(\mathrm{H}_{2} \mathrm{O}\right)_{4}$ & 1.2323 & 1.2358 & 1.0256 & 1.0148 \\
PSMA- $\left(\mathrm{H}_{2} \mathrm{O}\right)_{5}$ & 1.2332 & 1.2350 & 1.0288 & 1.0147 \\
\hline
\end{tabular}

Table 3. The chemical parameters of the complexes

\begin{tabular}{ccccccc}
\hline Complexes & $\begin{array}{c}\mathrm{E}_{\text {номо }} \\
(\mathrm{eV})\end{array}$ & $\begin{array}{c}\mathrm{E}_{\mathrm{LUMO}} \\
(\mathrm{eV})\end{array}$ & $\begin{array}{c}\Delta \mathrm{E} \\
(\mathrm{eV})\end{array}$ & $\begin{array}{c}\mathrm{A} \\
(\mathrm{eV})\end{array}$ & $\begin{array}{c}\mathrm{I} \\
(\mathrm{eV})\end{array}$ & $\begin{array}{c}\chi \\
(\mathrm{eV})\end{array}$ \\
\hline 0 & -6.508290 & -0.463756 & 6.044534 & 0.463756 & 6.50829 & -3.48602 \\
1 & -6.455376 & -0.574396 & 5.880980 & 0.574396 & 6.455376 & -3.51489 \\
2 & -6.497964 & -0.025598 & 6.472366 & 0.025598 & 6.497964 & -3.26178 \\
3 & -6.462384 & -0.018804 & 6.443580 & 0.018804 & 6.462384 & -3.24059 \\
4 & -6.423786 & -0.575764 & 5.848022 & 0.575764 & 6.423786 & -3.49978 \\
5 & -6.465953 & -0.595711 & 5.870242 & 0.595711 & 6.465953 & -3.53083 \\
\hline
\end{tabular}


to the individual PSMA structure, the reduced energy gap allowed the electron to be easily transferred in the complex structures.

The HOMO-LUMO results were also supported by the affinity energy, ionization energy, and electronegativity (A, I, and $\chi$, respectively). The affinity energy for the complex was enhanced with the increase in water molecules, which indicated the stronger the PSMA and water molecules were attracted and bound to each other [42-43]. The decrease in ionization energy represented that the complex was easier to transfer electrons [44-45]. Moreover, the electronegativity value became more negative with the increase in water molecules, demonstrating that the PSMA and the water molecules attracted each other [45]. Thus, the promising hydrogel is formed from a different electronegativity material with the target molecule to attract it into the matrix [16,46-47].

\section{NBO Analysis}

In this study, the natural orbitals involved in $\mathrm{H}-$ bonding interactions were investigated by the NBO approach with the DFT method to support interaction energy data. The analysis was done because the interaction energy result is insufficient to identify the hydrogen bond strength $[10,48]$. The type of hydrogen bonding interaction was characterized by the stabilizing energy value $\left(E^{(2)}\right)$ that represented the delocalization of electron from a donor (i) (a lone pair orbital (LP) or an occupied bond (BD)) to acceptor (j) (an unoccupied antibond orbital $\left(\mathrm{BD}^{\star}\right)$ ) (Table S2) $[9,13]$. From the NBO data, it has become clear that hydrogen bonds were formed between the PSMA and the water molecules and between the water molecules themselves. Moreover, the result supported the previous statement on the increase in intermolecular hydrogen bonds as donors and acceptors enhance.

The PSMA- $\left(\mathrm{H}_{2} \mathrm{O}\right)_{1}$ complex was stabilized by the carboxyl group $(\mathrm{C}=\mathrm{O}, \mathrm{O}-\mathrm{H})$ of PSMA and the $\mathrm{O}-\mathrm{H}$ groups in the water molecule. NBO data proved that interaction between $\mathrm{O} 7$ lone pair donating orbital and O65-H66 antibonding orbital was given a weaker stabilizing energy compared to O65 $\cdots$ H64 (LP(2) O65 $\rightarrow$ $\left.\mathrm{BD}^{\star}(\mathrm{O} 34-\mathrm{H} 64), 34 \mathrm{kcal} / \mathrm{mol}\right)$. A similar report was also stated for the PSMA- $\left(\mathrm{H}_{2} \mathrm{O}\right)_{2}$. In addition, there was an $\mathrm{H}_{2} \mathrm{O} \cdots \mathrm{H}_{2} \mathrm{O}$ interaction in PSMA- $\left(\mathrm{H}_{2} \mathrm{O}\right)_{2}$ complex that $\mathrm{LP}(1) \mathrm{O} 65$ contributed as the donor and $\mathrm{BD}^{*}(\mathrm{H} 68-\mathrm{O} 69)$ as the acceptor with an $\mathrm{E}^{(2)}$ of $7.7 \mathrm{kcal} / \mathrm{mol}$.

In PSMA- $\left(\mathrm{H}_{2} \mathrm{O}\right)_{3}$ complex, $\mathrm{LP}(1) \mathrm{O} 65, \mathrm{LP}(2) \mathrm{O} 65$, $\mathrm{LP}(2)$ O69 contributed as the donors and $\mathrm{BD}^{*}(\mathrm{H} 68-$ O69) and $\mathrm{BD}^{\star}(\mathrm{O} 72-\mathrm{H} 73)$ as the acceptors in the interaction between water molecules and participated to the stabilization by $6.50,14.15$, and $27.52 \mathrm{kcal} / \mathrm{mol}$, respectively. The carbonyl group of the PSMA structure contributed to intermolecular hydrogen bond interactions through $\mathrm{LP}(1) \mathrm{O} 7 \rightarrow \mathrm{BD}^{\star}(\mathrm{O} 65-\mathrm{H} 66), \mathrm{LP}(2)$ $\mathrm{O} 7 \rightarrow \mathrm{BD}^{*}(\mathrm{O} 65-\mathrm{H} 66), \mathrm{LP}(1) \mathrm{O} 23 \rightarrow \mathrm{BD}^{*}(\mathrm{O} 65-\mathrm{H} 67)$, and $\mathrm{LP}(2) \mathrm{O} 23 \rightarrow \mathrm{BD}^{*}(\mathrm{O} 65-\mathrm{H} 67)$ which the calculated secondary perturbation energies were 9.28, 9.41, 3.66, and $8.52 \mathrm{kcal} / \mathrm{mol}$, respectively. The carboxyl group via $\mathrm{O}-\mathrm{H}$ also participated in the hydrogen bonding as acceptors, while oxygen in water molecules had a role as donors. The energies of $\mathrm{LP}(1) \mathrm{O} 65 \rightarrow \mathrm{BD}^{*}(\mathrm{O} 34-\mathrm{H} 64)$ and $\mathrm{LP}(2) \mathrm{O} 65 \rightarrow \mathrm{BD}^{*}(\mathrm{O} 34-\mathrm{H} 64)$ were about 4.97 and $12.17 \mathrm{kcal} / \mathrm{mol}$, respectively. In addition, LP(2) O72 $\rightarrow$ $\mathrm{BD}^{*}(\mathrm{O} 17-\mathrm{H} 49)$ provided a stronger stabilization of $39.50 \mathrm{kcal} / \mathrm{mol}$, which is classified as a strong hydrogen bond.

The PSMA- $\left(\mathrm{H}_{2} \mathrm{O}\right)_{4}$ and the PSMA- $\left(\mathrm{H}_{2} \mathrm{O}\right)_{5}$ complex showed hydrogen bond interactions that resemble the PSMA- $\left(\mathrm{H}_{2} \mathrm{O}\right)_{3}$ because the two carboxylate groups in PSMA interacted with water molecules. The most considerable hydrogen bonding occurred on LP(2) $\mathrm{O} 72 \rightarrow \mathrm{BD}^{*}(\mathrm{O} 17-\mathrm{H} 49)$ in the PSMA- $\left(\mathrm{H}_{2} \mathrm{O}\right)_{4}$ and the PSMA- $\left(\mathrm{H}_{2} \mathrm{O}\right)_{5}$ complex with energy stability of 48.33 and $50.32 \mathrm{kcal} / \mathrm{mol}$, respectively. The increase in energy

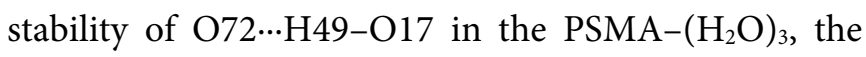
PSMA- $\left(\mathrm{H}_{2} \mathrm{O}\right)_{4}$, and the PSMA- $\left(\mathrm{H}_{2} \mathrm{O}\right)_{5}$ complexes caused an increase in the length of the $\mathrm{H} 49-\mathrm{O} 17$ bond and a shorter interaction distance (Table 1 and 2, respectively). The bond length in the range of 1.5-1.6 and energy stability of $>20 \mathrm{kcal} / \mathrm{mol}$ made the interaction in $\mathrm{O} 72 \cdots \mathrm{H} 49$ was categorized as a strong hydrogen bonding system [13]. High stabilization energy means that the stronger the hydrogen bonding interaction, the easier the proton transfer [10,49-51]. 
The NBO data could also explain the increase in length of $\mathrm{C} 5=\mathrm{O} 7$ in the PSMA- $\left(\mathrm{H}_{2} \mathrm{O}\right)_{1}$ to PSMA- $\left(\mathrm{H}_{2} \mathrm{O}\right)_{5}$ complexes by an increase in the stability energy on LP(1) $\mathrm{O} 7 \rightarrow \mathrm{BD}^{*}(\mathrm{O} 65-\mathrm{H} 66)$. Furthermore, the energy was in line with the increase in water molecules (n). Fig. 2 displayed the good correlation between $\mathrm{E}^{(2)}$ of $\mathrm{O} 7 \cdots \mathrm{H} 66$ and $\left(\mathrm{H}_{2} \mathrm{O}\right)_{\mathrm{n}}$ with an $\mathrm{R}^{2}=0.994$. Therefore, it can be inferred that the hydrogen bond interaction of the PSMA $\cdots \mathrm{H}_{2} \mathrm{O}$ complex was strong, which was great for maintaining water inside its three-dimensional matrix $[38,52]$.

\section{QTAIM Analysis}

The QTAIM analysis was conducted due to the study of hydrogen bonding interaction type at BCP. Therefore, essential topological parameters, such as $\nabla^{2} \rho$, $\rho, G, H, V$, and ratio $|V / G|$, were crucial to identify the $H-$ bond critical points $(3,-1)$ achieved from QTAIM computation [9]. The Multiwfn program calculated the QTAIM calculation. The BCP of PSMA- $\left(\mathrm{H}_{2} \mathrm{O}\right)_{n}$ complexes were presented in Fig. 3, whereas the parameters were displayed in Table S3.

According to $\mathrm{BCP}$ visualization, new hydrogen bonding was formed in PSMA- $\left(\mathrm{H}_{2} \mathrm{O}\right)_{n}$ complexes when water molecules were added. All BCP presented positive value from $\nabla^{2} \rho$, and major BCP showed negative value from $\mathrm{H}_{(\mathrm{BCP})}$. There were small portions of $\mathrm{BCP}$ that showed positive values from $\mathrm{H}_{(\mathrm{BCP})}$. Therefore, the
PSMA- $\left(\mathrm{H}_{2} \mathrm{O}\right)_{n}$ complexes were considered weak to medium interactions. It was also supported by the value of the $|V / G|$ ratio at most $\mathrm{BCPs}$ in the range of $1-2$, while the minority presented $|\mathrm{V} / \mathrm{G}|<1$. The QTAIM calculation supported the claim that the hydrogen bond of O7..H66 enhanced with the increase in the number of water molecules. The same thing was found in the O72 $\cdots \mathrm{H} 49$ bond in PSMA- $\left(\mathrm{H}_{2} \mathrm{O}\right)_{3}$, PSMA- $\left(\mathrm{H}_{2} \mathrm{O}\right)_{4}$, and PSMA- $\left(\mathrm{H}_{2} \mathrm{O}\right)_{5}$. The results showed that the hydrogen bond energy in the complex was in the range of -2.3407 to $-14.946 \mathrm{kcal} / \mathrm{mol}$. The results showed similar hydrogen

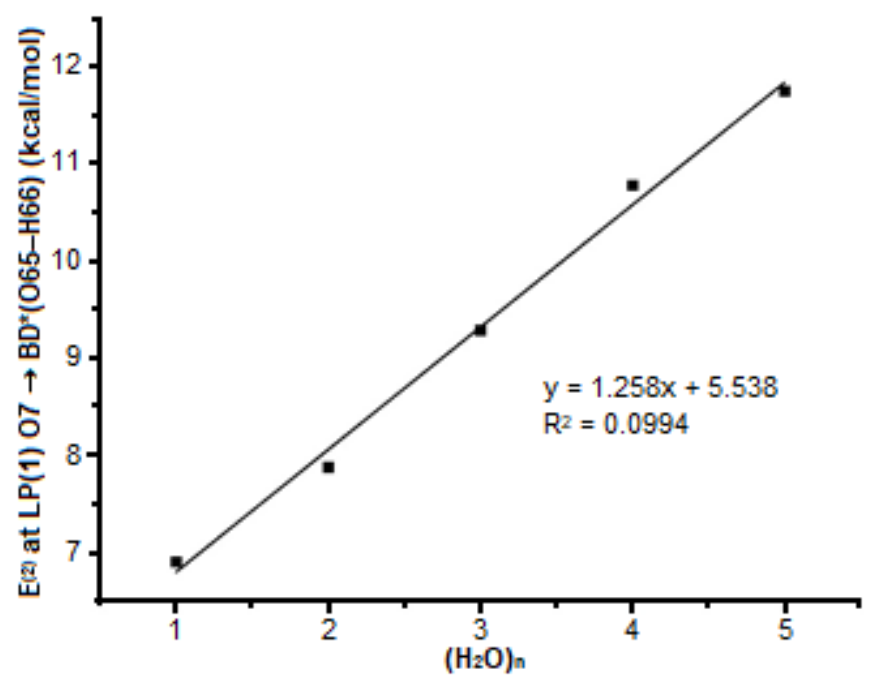

Fig 2. Correlation of the $\mathrm{E}^{(2)}$ of $\mathrm{O} 7 \cdots \mathrm{H} 66$ versus the number of $\mathrm{H}_{2} \mathrm{O}$ molecules within PSMA- $\left(\mathrm{H}_{2} \mathrm{O}\right)_{n}$ complexes

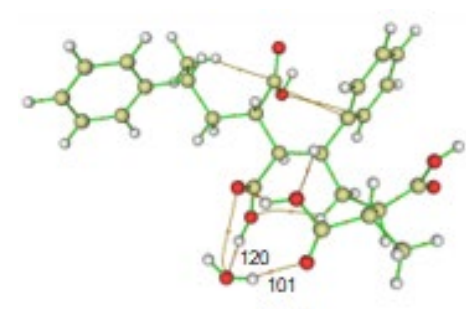

(a)

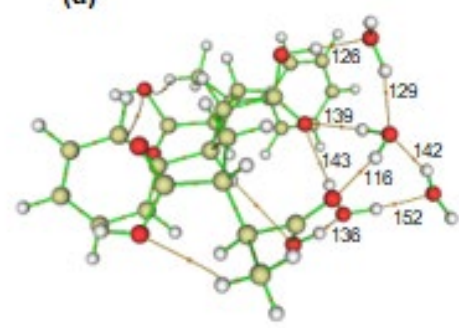

(d)

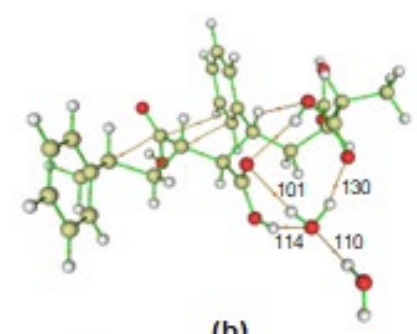

(b)

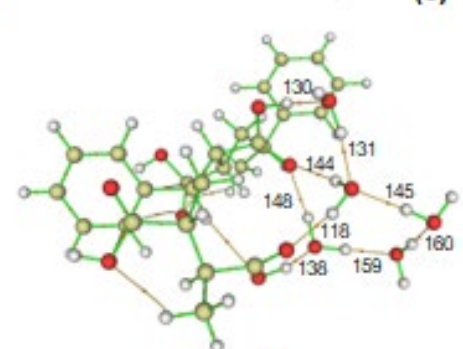

(e)

Fig 3. $\mathrm{BCP}$ for (a) PSMA- $\left(\mathrm{H}_{2} \mathrm{O}\right)_{1}$, (b) PSMA- $\left(\mathrm{H}_{2} \mathrm{O}\right)_{2}$, (c) PSMA- $\left(\mathrm{H}_{2} \mathrm{O}\right)_{3}$, (d) PSMA- $\left(\mathrm{H}_{2} \mathrm{O}\right)_{4}$, and (e) PSMA- $\left(\mathrm{H}_{2} \mathrm{O}\right)_{5}$ 
bonding values in previous computational studies $[9,16,53]$ (Table S4). In addition, both NBO and QTAIM analyses showed the strongest intermolecular hydrogen bond at $\mathrm{O}_{72} \cdots \mathrm{H}_{49}$ in PSMA- $\left(\mathrm{H}_{2} \mathrm{O}\right)_{5}$ complex. The QTAIM results successfully demonstrated that PSMA was a potential polymeric material as a hydrogel due to its ability to make medium hydrogen bonds with water molecules.

\section{RDG and NCl Analyses}

The NCI study described intra-intermolecular interactions and assessed the nature of weak interactions in PSMA- $\left(\mathrm{H}_{2} \mathrm{O}\right)_{n}$ complexes. The NCI index gave additional information regarding non-covalent interaction based on RDG [54]. The 2D RDG graph of sign $\left(\lambda_{2}\right) \rho_{(r)}$ versus RDG value was plotted in Fig. 4. Blue, green, and red colors in the RDG graph represented the (a) PSMA

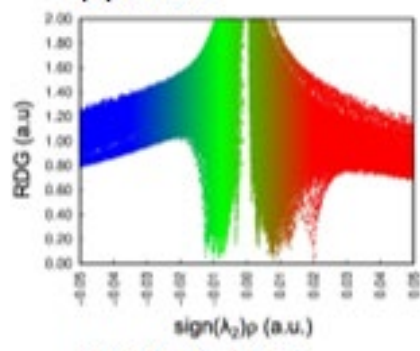

(d) PSMA- $\left(\mathrm{H}_{2} \mathrm{O}\right)_{3}$

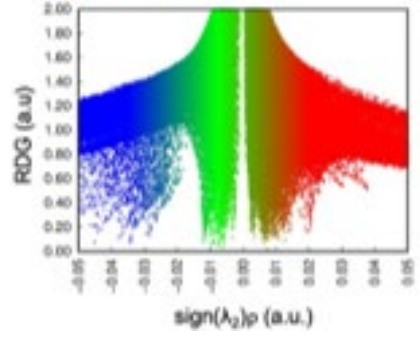

(b) PSMA- $\left(\mathrm{H}_{2} \mathrm{O}\right)$

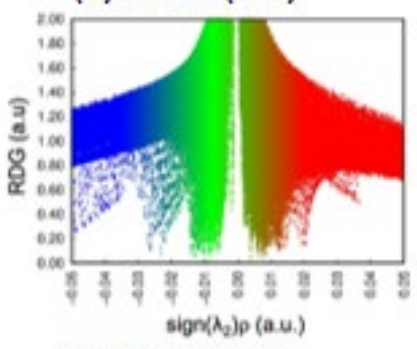

(e) PSMA- $\left(\mathrm{H}_{2} \mathrm{O}\right)_{4}$

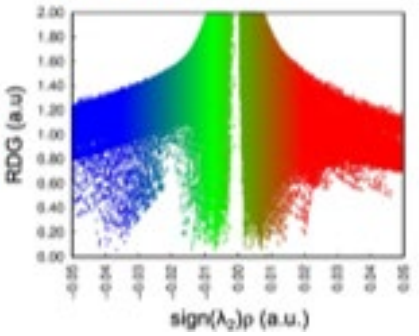

(c) PSMA- $\left(\mathrm{H}_{2} \mathrm{O}\right)_{2}$

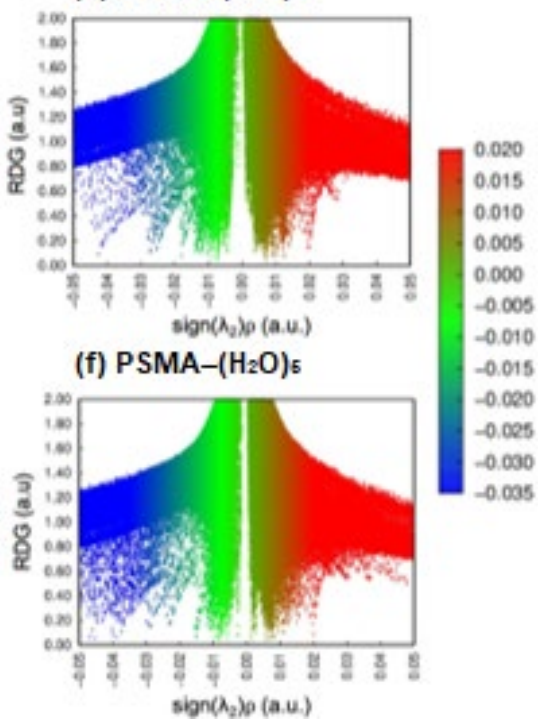

Fig 4. $\mathrm{RDG}$ 's scatter graphs of PSMA and PSMA- $\left(\mathrm{H}_{2} \mathrm{O}\right)_{\mathrm{n}}$ complexes; $\mathrm{n}=1-5$

(a) PSMA

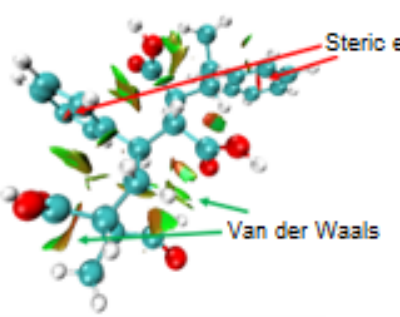

(d) PSMA- $\left(\mathrm{H}_{2} \mathrm{O}\right)_{3}$

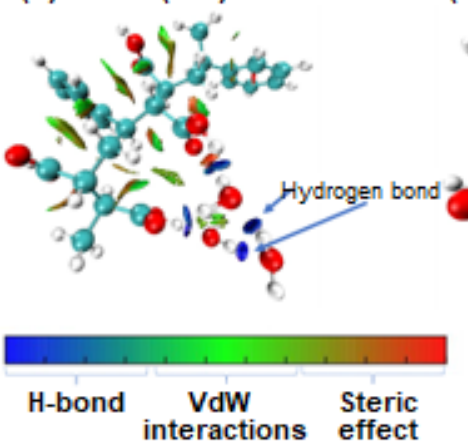

(b) PSMA- $\left(\mathrm{H}_{2} \mathrm{O}\right)$

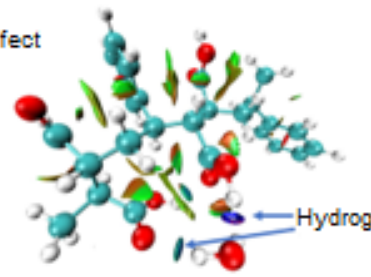

(e) PSMA- $\left(\mathrm{H}_{2} \mathrm{O}\right)_{4}$

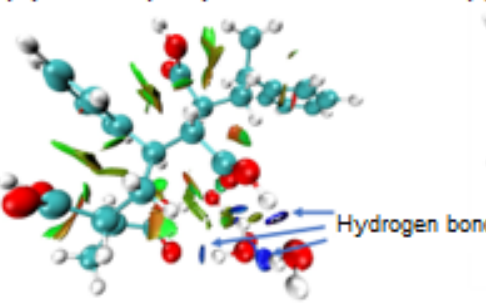

Hydrogen atom (c) PSMA- $\left(\mathrm{H}_{2} \mathrm{O}\right)_{2}$

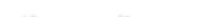

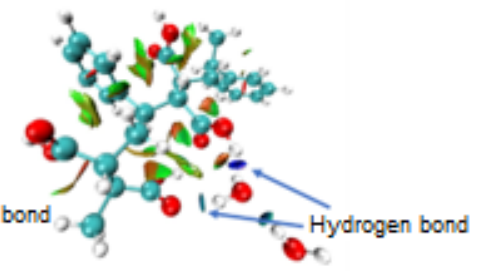

(f) PSMA-( $\left.\mathrm{H}_{2} \mathrm{O}\right)_{6}$

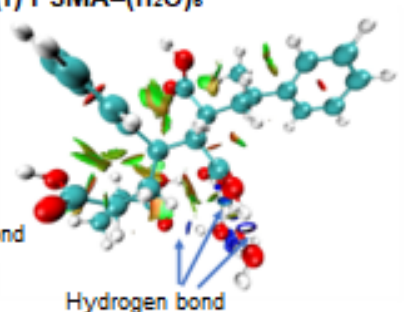

Hydrogen bond

oxygen atom

Carbon atom

Fig 5. Three-dimensional RDG isosurfaces of PSMA and PSMA- $\left(\mathrm{H}_{2} \mathrm{O}\right)_{n}$ complexes; $\mathrm{n}=1-5$ 
hydrogen bond, the VdW interaction, and the steric effect, respectively. Visualization of non-covalent interaction was performed with a three-dimensional (3D) RDG isosurface (Fig. 5) to provide a deeper understanding. In the 3D RDG graph, green, blue, and red represented the VdW interaction, H-bond, and steric effect.

The PSMA graph emphasized that VdW interaction and steric effect were dominant in the structure (Fig. 4(a)). The intramolecular bond of $\mathrm{O} 23 \cdots \mathrm{H} 49$ was shown as VdW interaction (green color) (Fig. 5(a)). The steric effect occurred due to the presence of phenyl rings of the PSMA structure. On the other hand, the PSMA- $\left(\mathrm{H}_{2} \mathrm{O}\right)_{n}$ complexes became denser in the blue and green areas (Fig. $4(\mathrm{~b}-\mathrm{e}))$. The trends indicated an increase in the number of hydrogen bonds and VdW interaction. Fig. 5(b-e) supported the explanation by showing more blue and green colors. The computational investigation revealed that PSMA was able to interact strongly with water molecules. These results also reinforced the previous experimental research that stated the PSMA hydrogel with polyethylene glycol as a crosslinker could swell up to $14.58 \%$ [8]. The other research of PSMA hydrogel presented the total water absorption ratio in the range of $13.6-71 \mathrm{~g} / \mathrm{g}[55]$.

\section{- CONCLUSION}

The in silico study of PSMA- $\left(\mathrm{H}_{2} \mathrm{O}\right)_{\mathrm{n}}$ complexes were carried out to evaluate the interaction between PSMA and $\left(\mathrm{H}_{2} \mathrm{O}\right)_{\mathrm{n}}(\mathrm{n}=1-5)$. The calculation was conducted by the DFT method and $6-311 \mathrm{G}^{* *}$ basis set. By the structure optimization of PSMA dimer, water, and PSMA- $\left(\mathrm{H}_{2} \mathrm{O}\right)_{n}$ complexes, serial properties of those complexes were attained. The hydration affects the intramolecular structure of PSMA. The interaction between PSMA and water molecules was conducted at carboxyl groups. The increase in the number of water molecules enhanced the interaction energy and reactivity of PSMA- $\left(\mathrm{H}_{2} \mathrm{O}\right)_{n}$ complexes. The intermolecular hydrogen bonds in the complexes were evaluated by NBO, AIM, and RDG-NCI analyses. The easiest electron lone-pairs donating was found on PSMA$\left(\mathrm{H}_{2} \mathrm{O}\right)_{5}$ complex through $\mathrm{LP}(2) \mathrm{O} 72 \rightarrow \mathrm{BD}^{*}(\mathrm{O} 17-\mathrm{H} 49)$ with the stabilizing energy of $50.32 \mathrm{kcal} / \mathrm{mol}$. The AIM results also approved the statement. Moreover, the RDG and NCI analyses supported the results by improving hydrogen bond interactions as the water molecule increased. The examination categorized the hydrogen bond between PSMA and water as the medium to the strong bond interaction. All data presented indicate PSMA is a potential polymer to be developed in an aqueous solution

\section{- ACKNOWLEDGMENTS}

The research was funded by Atma Jaya Catholic University of Indonesia (Number: 0659/III/LPPMPM.10.01/05/2021).

\section{- REFERENCES}

[1] Anugrah, D.S.B., Ramesh, K., Kim, M., Hyun, K., and Lim, K.T., 2019, Near-infrared light-responsive alginate hydrogels based on diselenide-containing cross-linkage for on demand degradation and drug release, Carbohydr. Polym., 223, 115070.

[2] Sung, Y.K., and Kim, S.W., 2020, Recent advances in polymeric drug delivery systems, Biomater. Res., $24(1), 12$.

[3] Jia, Y.G., Jin, J., Liu, S., Ren, L., Luo, J., and Zhu, X.X., 2018, Self-healing hydrogels of low molecular weight poly(vinyl alcohol) assembled by host-guest recognition, Biomacromolecules, 19 (2), 626-632.

[4] Deák, Á., Sebők, D., Csapó, E., Bérczi, A., Dékány, I., Zimányi, L., and Janovák, L., 2019, Evaluation of pH-responsive poly(styrene-co-maleic acid) copolymer nanoparticles for the encapsulation and $\mathrm{pH}$-dependent release of ketoprofen and tocopherol model drugs, Eur. Polym. J., 114, 361-368.

[5] Larson, N., Greish, K., Bauer, H., Maeda, H., and Ghandehari, H., 2011, Synthesis and evaluation of poly(styrene-co-maleic acid) micellar nanocarriers for the delivery of tanespimycin, Int. J. Pharm., 420 (1), 111-117.

[6] Fang, J., Gao, S., Islam, R., Nema, H., Yanagibashi, R., Yoneda, N., Watanabe, N., Yasuda, Y., Nuita, N., Zhou, J.R., and Yokomizo, K., 2021, Styrene maleic acid copolymer-based micellar formation of temoporfin (SMA@mTHPC) behaves as a nanoprobe for tumor-targeted photodynamic 
therapy with a superior safety, Biomedicines, 9 (10), 1493.

[7] Moghadam, P.N., Azaryan, E., and Zeynizade, B., 2010, Investigation of poly(styrene-alt-maleic anhydride) copolymer for controlled drug delivery of ceftriaxone antibiotic, J. Macromol. Sci., Part A: Pure Appl. Chem., 47 (8), 839-848.

[8] Anugrah, D.S.B., Patil, M.P., Li, X., Le, C.M.Q., Ramesh, K., Kim, G.D., Hyun, K., and Lim, K.T., 2020, Click-cross-linked, doxorubicin-loaded hydrogels based on poly(styrene-alt-maleic anhydride), eXPRESS Polym. Lett., 14 (3), 248-260.

[9] Safia, H., Ismahan, L., Abdelkrim, G., Mouna, C., Leila, N., and Fatiha, M., 2019, Density functional theories study of the interactions between host $\beta$ cyclodextrin and guest 8-anilinonaphthalene-1sulfonate: Molecular structure, HOMO, LUMO, NBO, QTAIM and NMR analyses, J. Mol. Liq., 280, 218-229.

[10] Hammami, F., Ghalla, H., and Nasr, S., 2015, Intermolecular hydrogen bonds in urea-water complexes: DFT, NBO, and AIM analysis, Comput. Theor. Chem., 1070, 40-47.

[11] Venkataramanan, N.S., Suvitha, A., and Kawazoe, Y., 2017, Intermolecular interaction in nucleobases and dimethyl sulfoxide/water molecules: A DFT, NBO, AIM and NCI analysis, J. Mol. Graphics Modell., 78, 48-60.

[12] Deka, B.C., and Bhattacharyya, P.K., 2017, DFT study on host-guest interaction in chitosan-amino acid complexes, Comput. Theor. Chem., 1110, 40-49.

[13] Rahmawati, S., Radiman, C.L., and Martoprawiro, M.A., 2018, Density functional theory (DFT) and natural bond orbital (NBO) analysis of intermolecular hydrogen bond interaction in "Phosphorylated nata de coco - water", Indones. J. Chem., 18 (1), 173-178.

[14] Cortes, E., Márquez, E., Mora, J.R., Puello, E., Rangel, N., De Moya, A., and Trilleras, J., 2019, Theoretical study of the adsorption process of antimalarial drugs into acrylamide-base hydrogel model using DFT methods: The first approach to the rational design of a controlled drug delivery system, Processes, 7 (7), 396.
[15] Costa, M.P.M., Prates, L.M., Baptista, L., Cruz, M.T.M., and Ferreira, I.L.M., 2018, Interaction of polyelectrolyte complex between sodium alginate and chitosan dimers with a single glyphosate molecule: A DFT and NBO study, Carbohydr. Polym., 198, 51-60.

[16] Siahaan, P., Sasongko, N.A., Lusiana, R.A., Prasasty, V.D., and Martoprawiro, M.A., 2021, The validation of molecular interaction among dimer chitosan with urea and creatinine using density functional theory: In application for hemodyalisis membrane, Int. J. Biol. Macromol., 168, 339-349.

[17] Deka, B.C., and Bhattacharyya, P.K., 2015, Understanding chitosan as a gene carrier: A DFT study, Comput. Theor. Chem., 1051, 35-41.

[18] Martins, J.B.L., Quintino, R.P., Politi, J.R.S., Sethio, D., Gargano, R., and Kraka, E., 2020, Computational analysis of vibrational frequencies and rovibrational spectroscopic constants of hydrogen sulfide dimer using MP2 and $\operatorname{CCSD}(\mathrm{T})$, Spectrochim. Acta, Part A, 239, 118540.

[19] Nikoo, S., and Rawson, J.M., 2021, Assessment of computational methods for calculating accurate noncovalent interaction energies in 1,2,3,5-dithiadiazolyl radicals, Cryst. Growth Des., 21 (9), 4878-4891.

[20] Lei, J., Zhang, J., Feng, G., Grabow, J.U., and Gou, Q., 2019, Conformational preference determined by inequivalent n-pairs: Rotational studies on acetophenone and its monohydrate, Phys. Chem. Chem. Phys., 21 (41), 22888-22894.

[21] Řezáč, J., and Hobza, P., 2016, Benchmark calculations of interaction energies in noncovalent complexes and their applications, Chem. Rev., 116 (9), 5038-5071.

[22] Li, L., Wu, C., Wang, Z., Zhao, L., Li, Z., Sun, C., and Sun, T., 2015, Density functional theory (DFT) and natural bond orbital (NBO) study of vibrational spectra and intramolecular hydrogen bond interaction of 1-ornithine-l-aspartate, Spectrochim. Acta, Part A, 136, 338-346.

[23] Abou-Yousef, H., Dacrory, S., Hasanin, M., Saber, E., and Kamel, S., 2021, Biocompatible hydrogel based on aldehyde-functionalized cellulose and 
chitosan for potential control drug release, Sustainable Chem. Pharm., 21, 100419.

[24] Awasthi, S., Gaur, J.K., Pandey, S.K., Bobji, M.S., and Srivastava, C., 2021, High-strength, strongly bonded nanocomposite hydrogels for cartilage repair, ACS Appl. Mater. Interfaces, 13 (21), 24505-24523.

[25] Rincón, D.A., Doerr, M., and Daza, M.C., 2021, Hydrogen bonds and $n \rightarrow \pi^{*}$ interactions in the acetylation of propranolol catalyzed by Candida antarctica lipase B: A QTAIM study, ACS Omega, 6 (32), 20992-21004.

[26] Emamian, S., Lu, T., Kruse, H., and Emamian, H., 2019, Exploring nature and predicting strength of hydrogen bonds: A correlation analysis between atoms-in-molecules descriptors, binding energies, and energy components of symmetry-adapted perturbation theory, J. Comput. Chem., 40 (32), 2868-2881.

[27] Shen, J., Wu, X., Yu, J., Yin, F., Hao, L., Lin, C., Zhu, L., Luo, C., Zhang, C., and Xu, F., 2021, Hydrogen bonding interactions between arsenious acid and dithiothreitol/dithioerythritol at different $\mathrm{pH}$ values: A computational study with an explicit solvent model, New J. Chem., 45 (43), 20181-20192.

[28] An, X., Kang, Y., and Li, G., 2019, The interaction between chitosan and tannic acid calculated based on the density functional theory, Chem. Phys., 520, 100107.

[29] Cao, S., Wang, J., Ding, Y., Sun, M., and Ma, F., 2017, Visualization of weak interactions between quantum dot and graphene in hybrid materials, Sci. Rep., 7 (1), 417.

[30] Wang, J., Wang, C., Zhang, H., Liu, Y., and Shi, T., 2021, Mass spectral and theoretical investigations of the transient proton-bound dimers on the cleavage processes of the peptide GHK and its analogues, RSC Adv., 11 (7), 4077-4086.

[31] Thakur, T.S., and Singh, S.S., 2015, Studying the role of $\mathrm{C}=\mathrm{O} \cdots \mathrm{C}=\mathrm{O}, \mathrm{C}=\mathrm{O} \cdots \mathrm{N}-\mathrm{O}$, and $\mathrm{N}-\mathrm{O} \cdots \mathrm{N}-\mathrm{O}$ dipoledipole interactions in the crystal packing of 4nitrobenzoic acid and 3,3'-dinitrobenzophenone polymorphs: An experimental charge density study, Cryst. Growth Des., 15 (7) 3280-3292.
[32] Cisneros, G.A., Wikfeldt, K.T., Ojamäe, L., Lu, J., Xu, Y., Torabifard, H., Bartók, A.P., Csányi, G., Molinero, V., and Paesani, F., 2016, Modeling molecular interactions in water: From pairwise to many-body potential energy functions, Chem. Rev., 116 (13), 7501-7528.

[33] Lusiana, R.A., Sasongko, N.A., Sangkota, V.D.A., Prasetya, N.B.A., Siahaan, P., Kiswandono, A.A., and Othman, M.H.D., 2020, In-vitro study of polysulfone-polyethylene glycol/chitosan (PEGPSf/CS) membranes for urea and creatinine permeation, J. Kim. Sains Apl., 23 (8), 283-289.

[34] Lima, F.C.D.A., Alvim, R.S., and Miranda, C.R., 2017, From single asphaltenes and resins to nanoaggregates: A computational study, Energy Fuels, 31 (11), 11743-11754.

[35] Verweel, H.J., and Macgillavry, C.H., 1938, Crystal structure of succinic acid, Nature, 142 (3586), 161162.

[36] Siboro, S.A.P., Anugrah, D.S.B., Ramesh, K., Park, S.H., Kim, H.R., and Lim, K.T., 2021, Tunable porosity of covalently crosslinked alginate-based hydrogels and its significance in drug release behavior, Carbohydr. Polym., 260, 117779.

[37] Eivazzadeh-Keihan, R., Khalili, F., Khosropour, N., Aliabadi, H.A.M., Radinekiyan, F., Sukhtezari, S., Maleki, A., Madanchi, H., Hamblin, M.R., Mahdavi, M., Haramshahi, S.M.A., Shalan, A.E., and Lanceros-Méndez, S., 2021, Hybrid bionanocomposite containing magnesium hydroxide nanoparticles embedded in a carboxymethyl cellulose hydrogel plus silk fibroin as a scaffold for wound dressing applications, ACS Appl. Mater. Interfaces, 13 (29), 33840-33849.

[38] Zhang, Y.S., and Khademhosseini, A., 2017, Advances in engineering hydrogels, Science, 356 (6337), eaaf3627.

[39] Liu, C., Min, F., Liu, L., and Chen, J., 2019, Density functional theory study of water molecule adsorption on the a-quartz (001) surface with and without the presence of $\mathrm{Na}^{+}, \mathrm{Mg}^{2+}$, and $\mathrm{Ca}^{2+}, A C S$ Omega, 4 (7), 12711-12718. 
[40] Chen, M., Ko, H.Y., Remsing, R.C., Calegari Andrade, M.F., Santra, B., Sun, Z., Selloni, A., Car, R., Klein, M.L., Perdew, J.P., and Wu, X., 2017, Ab initio theory and modeling of water, Proc. Natl. Acad. Sci. U.S.A., 114 (41), 10846-10851.

[41] Rieloff, E., Tully, M.D., and Skepö, M., 2019, Assessing the intricate balance of intermolecular interactions upon self-association of intrinsically disordered proteins, J. Mol. Biol., 431 (3), 511-523.

[42] Uto, T., and Yui, T., 2018, DFT optimization of isolated molecular chain sheet models constituting native cellulose crystal structures, ACS Omega, 3 (7), 8050-8058.

[43] You, W., Liu, Y., Howe, J.D., and Sholl, D.S., 2018, Competitive binding of ethylene, water, and carbon monoxide in metal-organic framework materials with open Cu sites, J. Phys. Chem. C, 122 (16), 8960-8966.

[44] Gershoni-Poranne, R., Rahalkar, A.P., and Stanger, A., 2018, The predictive power of aromaticity: quantitative correlation between aromaticity and ionization potentials and HOMO-LUMO gaps in oligomers of benzene, pyrrole, furan, and thiophene, Phys. Chem. Chem. Phys., 20 (21), 14808-14817.

[45] Li, H., Zhu, W., Zhu, S., Xia, J., Chang, Y., Jiang, W., Zhang, M., Zhou, Y., and Li, H., 2016, The selectivity for sulfur removal from oils: An insight from conceptual density functional theory, AIChE J., 62 (6), 2087-2100.

[46] Subramanian, B., Rameshbabu, A.P., Ghosh, K., Jha, P.K., Jha, R., Murugesan, S., Chattopadhyay, S., Dhara, S., Mondal, K.C., Basak, P., and Guha, S.K., 2019, Impact of styrene maleic anhydride (SMA) based hydrogel on rat fallopian tube as contraceptive implant with selective antimicrobial property, Mater. Sci. Eng., C, 94, 94-107.
[47] Ngo, T.M.P., Dang, T.M.Q., Tran, T.X., and Rachtanapun, P., 2018, Effects of zinc oxide nanoparticles on the properties of pectin/alginate edible films, Int. J. Polym. Sci., 2018, 5645797.

[48] Ghosh, S., Chopra, P., and Wategaonkar, S., 2020, $\mathrm{C}-\mathrm{H} \cdots \mathrm{S}$ Interaction exhibits all the characteristics of conventional hydrogen bonds, Phys. Chem. Chem. Phys., 22 (31), 17482-17493.

[49] Yamada, Y., Goto, Y., Fukuda, Y., Ohba, H., and Nibu, Y., 2020, Excited-state dynamics affected by switching of a hydrogen-bond network in hydrated aminopyrazine clusters, J. Phys. Chem. A, 124 (48), 9963-9972.

[50] Lütteke, T., and Martin, F., 2015, Glycoinformatics, Humana Press, New Jersey, US.

[51] Li, Z.J., Srebnik, S., and Rojas, O.J., 2021, Revisiting cation complexation and hydrogen bonding of single-chain polyguluronate alginate, Biomacromolecules, 22 (9), 4027-4036.

[52] Li, J., and Mooney, D.J., 2016, Designing hydrogels for controlled drug delivery, Nat. Rev. Mater., 1 (12), 16071.

[53] Wang, B., Jiang, W., Dai, X., Gao, Y., Wang, Z., and Zhang, R.Q., 2016, Molecular orbital analysis of the hydrogen bonded water dimer, Sci. Rep., 6 (1), 22099.

[54] Akman, F., Issaoui, N., and Kazachenko, A.S., 2020, Intermolecular hydrogen bond interactions in the thiourea/water complexes (Thio- $\left.\left(\mathrm{H}_{2} \mathrm{O}\right)_{\mathrm{n}}\right)(\mathrm{n}=1, \cdots$, 5): X-ray, DFT, NBO, AIM, and RDG analyses, $J$. Mol. Model., 26 (6), 161.

[55] Tang, C., Ye, S., and Liu, H., 2007, Electrospinning of poly(styrene-co-maleic anhydride) (SMA) and water-swelling behavior of crosslinked/hydrolyzed SMA hydrogel nanofibers, Polymer, 48 (15) 44824491. 